\title{
ENSAIO SOBRE A FILOSOFIA DAS LÍNGUAS
}

\section{ESSAY ON THE PHILOSOPHY OF LANGUAGES}

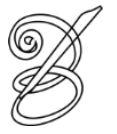 \\ Emanuel BRITO* \\ Universidade Federal Fluminense \\ Niterói, Rio de Janeiro, Brasil
}

\begin{abstract}
Resumo: Apresento tradução do texto de Melchiorre Cesarotti, em que o autor discorre sobre as expressões peculiares de um determinado idioma, os chamados idiotismos. Cesarotti avalia a pertinência de se traduzir e incorporar na língua de chegada os idiotismos pertencentes à categoria do "retórico", isto é, aqueles não diretamente ligados à uma nação, mas a um potencial comunicativo sem fronteiras.
\end{abstract}

Palavras-chave: Estudos da tradução. Melchiorre Cesarotti. Idiotismos.

Abstract: I present a translation of the text by Melchiorre Cesarotti, in which the author discusses the peculiar expressions of a given language, the so-called idioms. Cesarotti assesses the relevance of translating and incorporating in target language the idioms belonging to the "rhetorical" category, that is, those not directly linked to a nation, but to a communicative potential without borders.

Keywords: Translation studies. Melchiorre Cesarotti. Idioms.

RECEBIDO EM: 5 de setembro de 2019

ACEITO EM: 25 de novembro de 2019

PUBLICADO EM: março 2020 
$\mathrm{M}$ elchiorre Cesarotti (1730-1808) foi tradutor e literato de maior relevância entre os iluministas italianos. Suas contribuições no campo linguístico-literário são comparáveis, na Itália, àquelas expostas por Dante Alighieri (Convívio e De vulgari Eloquentia) e por Pietro Bembo (Prosas sobre a língua vulgar). Além de ter feito uma tradução em prosa da Ilíada, Cesarotti aprimorou sua poética traduzindo os poemas de Ossian, lendário bardo gaélico que teria vivido no século III. Entre as suas principais obras, destaca-se o vasto tratado Ensaio sobre a filosofia das línguas, do qual apresentamos aqui um pequeno trecho. Nesse, o papel do tradutor é visto como de grande importância no desenvolvimento das aptidões elocutórias de uma língua, sendo valorizada a capacidade que a tradução tem de potencializar aquilo que ele chama de "flexibilização" e "fecundidade", em detrimento dos preconceitos de uma visão purista da língua. O texto de partida é aqui selecionado por valorizar o papel do tradutor enquanto escritor que, numa tradição ciceroniana, não deve estar necessariamente preso "à letra do original", mas manter seu método "fiel ao espírito" do texto. ${ }^{1}$ Além disso, o ponto de vista de Cesarotti pode ser ainda aproximado de uma tradição horaciana, em que se considera enriquecer a língua de chegada pela felicidade das escolhas literárias. ${ }^{2}$

Saggio sulla filosofia delle lingue

Applicato alla lingua italiana

[...]

III, XVII.

Ma perché le nostre avversioni o parzialità abbiano qualche miglior fondamento, gioverà qui di ricordare che gl'idiotismi, secondo la divisione da noi fatta nella parte seconda, son di due specie, grammaticali e rettorici. I primi essendo, come abbiam detto, insignificanti, o non significando nulla di più d'altri analoghi che corrono in ciascheduna lingua, quand'anche potessero ugualmente bene trasportarsi dall'una all'altra, ragion vuole che si lascino
Ensaio sobre a filosofia das línguas

Aplicado à língua italiana ${ }^{7}$

[...]

III, XVII.

Mas para que as nossas aversões ou parcialidades tenham um melhor fundamento, será necessário aqui recordar que os idiotismos, segundo a divisão por nós feita na segunda parte, são de duas espécies: gramaticais e retóricos. ${ }^{8}$ Sendo os primeiros, como dissemos, insignificantes, ou não significando nada de mais em relação a outros análogos que ocorrem em qualquer língua quando esses também podem ser igualmente bem transportados de uma a 
senza invidia a quell'idioma a cui per natura appartengono. Chi dicesse triveloce o triforte in luogo di fortissimo e velocissimo, sarebbe inteso ugualmente, e la lingua italiana poteva in origine adottar ugualmente bene un modo che l'altro. Ma se la desinenza latina da lei prescelta spiega egregiamente lo stesso, sarebbe una stravaganza gratuita il sostituir al nostrale un segno straniero.

Ma gl'idiotismi rettorici essendo di natura diversa, possono e debbono meritare qualche privilegio. Sono essi configurazioni espressive, che accennano idee accessorie, atteggiano i sentimenti e ne rappresentano i diversi gradi e il modo particolare con cui ci affettano. Sotto questo punto di vista appartengono più all'eloquenza che alla lingua, e per conseguenza non sono propriamente più d'una nazion che dell'altra, ma di giurisdizione comune di chiunque sente o concepisce in un modo analogo. Conciossiaché l'eloquenza considerata nell'elocuzione, come nell'altre sue parti, abbraccia e comprende l'aggregato di tutti i mezzi possibili di rappresentare, d'illustrare, di dilettare e di muovere. Ora la lingua tanto dovrà dirsi migliore e più prossima alla perfezione, quanto sarà più pieghevole e più ricca di maniere che servano all'eloquenza, vale a dire a tutti i possibili bisogni della vita, dell'intelletto e del cuore. La cosa stessa non è veduta, né sentita, né concepita ugualmente da un uom volgare e da un dotto, da un rozzo outra, é racional que sejam deixados sem inveja a tal idioma ao qual pertencem por natureza. Se uma pessoa dissesse triveloz ou triforte ao invés de fortíssimo ou velocíssimo seria igualmente bem compreendida, e a língua italiana poderia na origem adotar igualmente bem um como o outro. E se a desinência latina por ela escolhida explica singularmente o mesmo, seria uma extravagância gratuita substituir o que é nosso com um sinal estrangeiro. ${ }^{9}$

Mas os idiotismos retóricos, sendo de natureza diversa, podem e devem merecer algum privilégio. Eles são configurações expressivas que indicam ideias acessórias, dispõem os sentimentos e deles representam os diversos graus, além do modo particular como nos afetam. Sob esse ponto de vista, pertencem mais à eloquência que à língua e, por consequência, não são propriamente mais de uma nação que de outra, mas de jurisdições comuns de quem quer que sinta ou conceba de modo análogo. Desse modo, a eloquência considerada na elocução, como nas suas outras partes, abraça e compreende o que está agregado de todos os meios possíveis de representar, de ilustrar, de deleitar e de demover. Por isso, a língua será tida como melhor e mais próxima à perfeição quanto mais for flexível e mais rica de maneiras que sirvam à eloquência, isto é, a todas as possíveis necessidades da vida, do intelecto e do coração. Uma mesma coisa não 
e da un colto, da un appassionato e da un freddo. Se ognuno ha un diritto naturale di sentir a suo modo, come non lo avrà parimente d'esprimersi adeguatamente? Ora in questa infinità d'uomini circondati da oggetti stessi, dotati degli stessi organi, posti in circostanze analoghe, soggetti infine alle stesse passioni diversificate soltanto nelle combinazioni e nei gradi, non è egli visibile che in tutte le nazioni debbono trovarsene molti che s'incontrino, dirò così, nell'atto individuale del concetto ${ }^{3}$ o del sentimento? Che importa se un popolo, che accidentalmente abbonda d'uomini della stessa tempera di spirito, usa un modo più

comunemente di quel che si faccia tra noi? Ogni nazione ben esaminata raccoglie nei caratteri tutte le altre: e che vuoi dire originale, se non uomo che ha qualche cosa nello spirito che lo distingue dai più? Se dunque la costituzione interna d'uno scrittore lo approssima talora ad un'altra nazione più che alla sua, com'è possibile che le sue maniere non sentano di questa natural somiglianza? Servendosi dell'espressioni che più gli convengono, egli non toglie l'altrui, anzi nemmeno lo riconosce per tale, ma si prevale del proprio ovunque lo trovi, né lo attinge dallo scarso erario d'una lingua, ma dai tesori inesausti dell'eloquenza, che lo presenta senza parzialità a chiunque ne sente il bisogno e sa farne uso. é vista, sentida ou concebida igualmente por um homem vulgar e por um instruído, por um rústico e por culto, por um apaixonado e por um frio. Se cada um tem o direito natural de sentir a seu modo, como não o terá, do mesmo modo, para se exprimir adequadamente? Por isso, nessa infinidade de homens circundados pelos mesmos objetos, dotados dos mesmos órgãos, postos em circunstâncias análogas, sujeitos às mesmas paixões diversificadas apenas nas combinações e nos graus, não é evidente que em todas as nações deve haver muitos que se encontrem, por assim dizer, no ato individual do conceito $^{10}$ ou do sentimento? $O$ que importa se um povo, que é acidentalmente repleto de homens da mesma coloração de espírito, emprega uma certa conduta de forma mais comum do que fazemos entre nós? Bem examinada, cada nação recolhe nos caráteres todas as outras: e o que quer dizer original, se não o homem que possui algo no espírito que o distingue dos demais? Se, então, a constituição interna de um escritor o aproxima às vezes a outra nação mais que à sua, como é possível que as suas maneiras não reflitam essa natural semelhança? Servindo-se das expressões que mais lhe convêm, ele não retira nada de ninguém; e nem mesmo assim o reconhece, mas se vale do que lhe é próprio onde quer que esteja; e não o adquire do escasso erário de uma língua, mas dos tesouros inexatos da 
Con questo ragionamento non si eloquência, que isso apresenta sem pretende di provare che sia lecito a parcialidade a quem quer que disso sinta a chicchesia di far un guazzabuglio babelico degl'idiotismi di varie lingue, ma solo che necessidade e disso saiba fazer uso.

non debbono né accettarsi indistintamente, né ciecamente proscriversi. Il gusto e l'analisi possono esserci di scorta per giudicar fondatamente non meno di questa che dell'altre parti della lingua. Sarebbe perciò per mio avviso utilissimo di esaminare i vari idiotismi delle lingue più celebri, secondo gli oggetti seguenti:

1. Osservare se appartengano all'una o all'altra delle due mentovate specie, ${ }^{4}$ e se alcuno della prima si fosse intruso nell'idioma nostro, farlo almeno conoscere, perché non si faccia rispettare come originario, e non si prenda per un gioiello della lingua.

2. Analizzar quelli della seconda specie, rilevarne con precisione il valore, gli usi e le minute differenze dagli altri della medesima classe nella stessa lingua: operazione necessaria alla finezza dell'intendimento e alla squisitezza del gusto.

3. Cercare se nella nostra lingua ve ne siano di realmente equivalenti, nel che suoi prendersi più d'uno abbaglio; farne un esatto ragguaglio coi nostri analoghi, notarne le somiglianze, le approssimazioni, i gradi maggiori di delicatezza o di forza.

4. Ove si scopra che la lingua nostra pretensão de provar que seja lícito a quem quer que seja fazer uma bagunça babélica dos idiotismos de várias línguas, mas apenas que esses não devem nem ser aceitos indistintamente e nem cegamente banidos. $\mathrm{O}$ gosto e a análise podem servir de escolta para julgar com fundamento não apenas nessa como nas outras partes da língua. A meu ver, seria, portanto, utilíssimo examinar os vários idiotismos das línguas mais célebres de acordo com os seguintes temas:

1. Observar se pertencem a uma ou a outra das duas mencionadas espécies; ${ }^{11}$ e se algum da primeira tiver se intrometido no nosso idioma, fazer ao menos com que isso seja reconhecido, de modo que não se faça respeitar como originário e não seja tido como uma joia da língua.

2. Analisar os da segunda espécie, delinear com precisão o seu valor, os usos e as mínimas diferenças em relação a outros da mesma classe na mesma língua: operação necessária à fineza do entendimento e à sutileza do gosto.

3. Examinar se na nossa língua existem equivalentes reais, onde se costuma incorrer em mais de um equívoco; fazer um confronto exato com os nossos análogos, manchi assolutamente d'alcuno di essi, 
esaminar prima qual effetto farebbe trasportato fra noi, e in quali luoghi potrebbe più opportunamente usarsi; indi cercar se sia già noto e comune e inteso generalmente $\mathrm{e}$ usato o nei discorsi familiari o negli scritti o nell'opere degli uomini colti, benché non per anco abbia avuto la sanzione legittima, della quale in tal caso si renderebbe degnissimo.

5. Se con ugual merito non fosse però ancora abbastanza comune, cercar se repugni alla struttura grammaticale della nostra lingua e sia perciò necessariamente da escludersi, o se possa non disconvenirle e adattarsi alla sua sintassi; se abbia nell'idioma nostro qualche costruzione 174 analoga che lo autorizzi, o se finalmente con qualche modificazione potesse addimesticarsi meglio e prender un'aria più nazionale, conservando o la stessa sua forza o almeno un grado assai prossimo.

XVIII.

Del resto per avvezzarsi a sentire squisitamente queste finezze, e per dar nuovi atteggiamenti e nuove ricchezze alla lingua, nulla gioverebbe maggiormente che l'instituire una serie di giudiziose traduzioni degli autori più celebri di tutte le lingue in tutti gli argomenti e in tutti gli stili; ${ }^{5}$ purché queste traduzioni non siano fatte né dai grammatici, né da quei tanti guastamestieri di cui abbonda l'Italia. Questo è il solo mezzo di conoscere con esattezza l'abbondanza e la notar as semelhanças, as aproximações, os maiores graus de delicadeza ou de força.

4. Onde se descobrir que a nossa língua carece absolutamente de algum desses, examinar primeiro qual efeito teria se transportado a nós, e em qual lugar poderia ser mais oportunamente usado; daí examinar se é já conhecido, comum e compreendido de modo geral, além de usado ou nos assuntos familiares, ou nos escritos, ou nas obras dos homens cultos, ainda que não tenha recebido a sanção legítima, da qual nesse caso se tornaria muito digno.

5. Se com tal mérito, porém, não for ainda bastante comum, observar se recusa a estrutura gramatical da nossa língua e deva, por isso, ser necessariamente eliminado, ou possa entrar em acordo e se adaptar à sua sintaxe; observar se há no nosso idioma alguma construção análoga que o autorize, ou se, finalmente, com alguma modificação poderia ser melhor domesticado e tomar uma veste mais nacional, conservando a sua mesma força ou, pelo menos, um grau muito próximo.

XVIII.

De resto, para se acostumar a ouvir sutilmente essas finezas, e para dar novos comportamentos e novas riquezas à língua, nada seria mais oportuno que instituir uma série de judiciosas traduções dos mais célebres autores de todas as línguas, em 
povertà rispettiva dell'idioma nostro, i suoi discapiti e i soccorsi che possono trarsi dalla sua fecondità, dall'uso libero delle sue forze o dall'accortezza nel giovarsi degli aiuti stranieri. La corrente degli scrittori, sia per mancanza d'un carattere proprio, sia per una meticulosa deferenza agli usi ordinari, accomoda le sue idee e i suoi sentimenti al modello comune, e non tenta nulla di più; quindi la lingua resta sempre sterile, uniforme, non abbastanza pieghevole. Un traduttore di genio prefiggendosi per una parte di gareggiar col suo originale, e sdegnando di restar soccombente; temendo per l'altra di riuscire oscuro e barbaro ai suoi nazionali, è costretto in certo modo a dar la tortura alla sua lingua per far conoscere a lei stessa tutta l'estensione delle sue forze, a sedurla accortamente per vincer le sue ritrosie irragionevoli e ravvicinarla alle straniere, a inventar vari modi di conciliazione e d'accordo, a renderla in fine più ricca di flessioni e d'atteggiamenti senza sfigurarla o sconciarla. La lingua d'uno scrittore mostra l'andatura d'un uomo che cammina equabilmente con una disinvoltura o compostezza uniforme; quella d'un traduttore rappresenta un atleta addestrato a tutti gli esercizi della ginnastica, che sa trar partito da ognun de' suoi membri, e si presta ad ogni movimento più strano così agevolmente che lo fa sempre parere il più naturale, anzi l'unico. ${ }^{6}$ todos os assuntos e em todos os estilos; ${ }^{12} \mathrm{com}$ a condição que essas traduções não sejam feitas nem por gramáticos, nem por tantos daqueles maus profissionais de que a Itália está repleta. Esse é o único meio de conhecer com exatidão a abundância e a pobreza respectiva do nosso idioma, os seus prejuízos e os socorros que podem ser trazidos da sua fertilidade, do uso livre das suas forças ou da astúcia em se beneficiar de ajudas estrangeiras. A linha dos escritores, seja por falta de um caráter próprio, seja por uma meticulosa deferência aos usos comuns, acomoda as suas ideias e os seus sentimentos no modelo comum, e não tenta nada a mais; portanto, a língua permanece sempre estéril, uniforme, não suficientemente flexível. Um tradutor de gênio - estabelecendo, por um lado, uma competição com o seu original e se recusando a se anular; temendo, por outro, resultar obscuro e bárbaro aos seus nacionais - é obrigado de certo modo a levar a sua língua à tortura, para fazer com que ela mesma conheça toda a extensão das suas forças, a seduzi-la astutamente para vencer as suas hesitações irracionais e reaproxima-la às estrangeiras, a inventar vários modos de conciliação e acordo, a torna-la por fim mais rica de flexões e de comportamentos sem desfigurá-la ou deturpá-la. A língua de um escritor mostra o andamento de um homem que caminha de modo constante com uma desenvoltura ou compostura uniforme; a de 
um tradutor representa um atleta adestrado a

todos os exercícios da ginástica, que sabe

tirar vantagem de cada um de seus membros

e se presta a cada movimento estranho de

modo tão ágil que o faz sempre parecer o

mais natural, ou melhor, o único. ${ }^{13}$

\section{REFERÊNCIA}

CESAROTTI, Melchiorre. Saggio sulla filosofia delle lingue. In: BIGI, Emilio (Org.). Dal Muratori al Cesarotti. Tomo IV. Critici e storici della poesia e delle arti nel secondo Settecento. Milão-Nápoles: Riccardo Ricciardi Ed., 1960, p. 389-393 [III XVII-XVIII].

\footnotetext{
* Emanuel França de BRITO - Licenciado em Letras (2005) pela Universidade Federal do Paraná. Mestre em Letras - Língua e Literatura Italiana (2010) pela Universidade de São Paulo. Doutor em Literatura Italiana (2015) pela mesma instituição. Realizou pesquisa de pós-doutorado (2015-2018) na Universidade de São Paulo. Professor de Língua e Literatura Italianas. Universidade Federal Fluminense, Instituto de Letras, Departamento de Letras Estrangeiras Modernas. Niterói, Rio de Janeiro, Brasil.

Currículo acadêmico: http://lattes.cnpq.br/3272050813548462

ORCID: https://orcid.org/0000-0003-4535-0285

E-mail: emanuelbrito@id.uff.br
}

${ }^{1}$ BIGI, Emilio (Org.). Dal Muratori al Cesarotti. Op. cit., p. 90. Para o filósofo, orador e tradutor romano Marco Túlio Cícero, uerbum pro uerbo ("palavra por palavra") é a postura que ele próprio decide não adotar ao traduzir "dois discursos notáveis e contrários entre si, um de Ésquino, outro de Demóstenes, autores dos mais eloquentes", preferindo agir como um orador e não apenas como intérprete. Cf. CÍCERO, Marco Túlio. De optimo genere oratorum (c. 46 a. C.) Trad. Brunno V. G. Vieira e Pedro C. Zoppi. In: Scientia Traductionis, n.10. PGET. Florianópolis, Universidade Federal de Santa Catarina, 2011. Grifos meus.

${ }^{2}$ Cf. HORÁCIO, De Arte Poetica liber, 55-56: ego cur, acquirere pauca si possum, invideor? ("Se posso propiciar [à língua latina] uma nova expressão, por que me impedir de fazê-lo"). Cf. Poesie di Ossian. Discorso premesso alla seconda edizione di Padova del 1772. In BIGI, Emilio (Org.). Dal Muratori al Cesarotti. Op. cit., p. 89.

${ }^{3}$ concetto: preferisco, con l'Ortolani, questa lezione che figura nella I edizione, in luogo di «concerto», che si legge nella II e in quella pisana.

${ }^{4}$ due... specie: grammatica e rettorica.

${ }^{5}$ Il sig. Napione riconosce anch'egli utilissime le traduzioni per migliorar la lingua, ma sembra che si restringa a quelle dei classici greci e latini. Pure cotesti autori hanno spesso dei modi tanto repugnanti a quelli della nostra lingua, quanto alcuno de' più disanaloghi fra le moderne. Se v'è un modo di ammorbidirli e conciliarli col genio italiano, perché la stessa industria non può esser ugualmente felice applicandola alla traduzione d'un autor francese, inglese o tedesco? Mi fu domandato dallo stesso critico qual aiuto io abbia tratto dagli autori francesi per la traduzione di Ossian: niuno certamente, ma non ne trassi niente di più dagl'italiani, né potea trarne: e se avessi avuto gli scrupoli di questo dotto scrittore, non mi sarei mai accinto a questo lavoro, poiché nulla potea darsi di più alieno dal genio della lingua e della poesia italiana delle maniere del bardo celtico. E pure... (C.).

${ }^{6}$ Per le idee espresse in questo paragrafo cfr. soprattutto il Discorso premesso alla traduzione di Ossian, il Ragionamento preliminare al corso ragionato di letteratura greca, e anche le lettere al Vannetti riportate esse pure in questo volume (...).

${ }^{7} \mathrm{O}$ texto de Cesarotti se coloca como um tratado que procura abordar o problema linguístico não como "ciência pura", mas "aplicada", o que fica evidente se observado o título desde a sua primeira edição, de 1785: Saggio sopra la lingua italiana. Essa intenção é também declarada na epístola de Cesarotti ao literato e conde Gian Francesco Galeani Napione, mencionado também em nota pelo autor: "Eu tinha me proposto a retirar a língua italiana do despotismo da autoridade e dos caprichos da moda e do uso para coloca-la sob o governo legítimo da 
razão e do gosto; a fixar os princípios filosóficos para julgar com fundamento sobre a beleza não arbitrária dos termos e para dirigir o manejo da língua em cada uma das suas partes [...]; a declarar guerra à superstição e à licença para substitui-las com uma temperada e judiciosa liberdade; a combater os excessos, os abusos, as prevenções de todas as espécies; a regular as disputas vãs, as cegas parcialidades; a aplicar por fim as teorias da filosofia à nossa língua, a indicar os meios de torná-la mais rica, mais desenvolta, mais vigorosa, mais apta a se manter em todos os temas e estilos em comparação aos mais célebres, como sem dúvida pode quando - sabiamente livre - souber fazer prevalecer a sua flexibilidade e fecundidade" (cf. Ed. BIGI, 1960, pp. 16-7). Nota do TRADUTOR.

${ }^{8} \mathrm{O}$ trecho apresentado estabelece uma distinção entre os dois tipos de idiotismo, locuções idiomáticas para as quais não há sentido literal equivalente em outra língua: um deles é chamado de "gênio gramatical", inalterável e dependente da estrutura formal da língua; outro, de "gênio retórico", passível de evolução e ligado ao conjunto de ideias e de disposições afetivas de uma nação (cf. PATRIZI, G. Cesarotti, M. In: Dizionario Biografico degli Italiani. Vol. 24. Roma: Ist. dell'Enciclopedia Italiana, 1980). Ambos os tipos se baseiam na potência criadora dos modelos da técnica, nomeados aqui numa perspectiva iluminista e quase romântica de "gênio". Nota do TRADUTOR.

${ }^{9}$ Em referência ao advérbio francês très, que identifica o superlativo absoluto quando precede um adjetivo. É de se observar, no entanto, que Cesarotti dedica muitas páginas do seu tratado para defender estrangeirismos e neologismos, que - uma vez admitidos numa língua - possuem a capacidade de produzir novas metáforas e derivações. Nota do TRADUTOR.

10 conceito: prefiro, assim como Ortolani, essa lição que figura na $1^{\mathrm{a}}$ edição, ao invés de "concerto", que se lê na $2^{\mathrm{a}}$ e na edição pisana. Nota do EDITOR (BIGI, 1960).

${ }^{11}$ Isto é, gramática e retórica. Nota do EDITOR (BIGI, 1960).

12 "O senhor Napione também reconhece como muito úteis as traduções para melhorar uma língua, mas parece se restringir àquelas dos clássicos gregos e latinos. Mas mesmo aqueles autores possuem, com frequência, modos tão repugnantes aos da nossa língua quanto alguns dos mais desencontrados entre as modernas. Se há um modo de amolece-los e conciliá-los ao gênio italiano, porque a mesma habilidade não pode ser igualmente feliz se aplicada à tradução de um autor francês, inglês ou alemão? A mim foi perguntado pelo mesmo crítico qual ajuda tive dos autores franceses para a tradução do Ossian: certamente nenhuma, mas não tive nenhuma a mais dos italianos, nem poderia ter; e se tivesse tido o escrúpulo desse erudito escritor, nunca teria me dedicado a tal trabalho, já que nada poderia haver de mais alheio ao gênio da língua e da poesia italiana que as maneiras do bardo céltico. Além disso [...]." Nota do AUTOR.

13 Para as ideias expressas neste parágrafo cf. sobretudo o Discorso introdutório à tradução de Ossian, o Ragionamento preliminare al corso ragionato di letteratura greca, além das cartas a Vannetti, também trazidas neste volume (...). Nota do EDITOR (BIGI, 1960). 